\title{
Provider Volumes and Surgical Outcomes in Total Hip and Knee Replacement
}

\author{
S. Rodriguez-Elizalde, R. Jenkinson, H. Kreder and J.M. Paterson \\ Division of Orthopaedic Surgery, Sunnybrook Health Sciences Centre, University of \\ Toronto; and the Institute for Clinical Evaluative Sciences \\ Canada
}

\section{Introduction}

There has been much discussion of the role of provider (both surgeon and hospital) surgical volumes and their effect on patient outcomes after total joint replacement (TJR) ${ }^{1-14}$. Common sense would suggest that individuals and institutions with greater experience should demonstrate reduced rates of complications and improved outcomes, however, in the setting of surgical outcomes, the question remains: does practice really make perfect? As medical costs continue to rise, institutions look for ways to optimize outcomes while decreasing complication rates and their associated financial and legal liabilities. There is ongoing debate as to whether the centralization of hospital resources to create large volume regional specialty centers and the sub-specialization of surgeons to increase their procedure volumes is an effective means of reducing cost and complications, $2,5,7,12$. Potential disadvantages of such centralization include increased wait times and travel distances for patients, and the possible closure of viable institutions. While most would likely agree that a volume exists below which procedure performance is suboptimal, where this threshold lies with respect to surgeon and institutional volumes in the field of hip and knee arthroplasty has yet to be defined.

Much of the literature on surgical volume-outcome associations comes from our colleagues in cardio-vascular, thoracic surgery and general surgery ${ }^{15}$. The early studies in this field were landmark in that they demonstrated a clear-cut reduction in mortality for procedures performed in specialized centers and by high volume surgeons ${ }^{15}$. In the past few decades, the frequency of total hip and knee arthroplasty has increased dramatically and these procedures are now considered among the most successful and reproducible medical procedures routinely performed 5,14, Overall, complication rates are low and consequently demonstrating volume-outcome associations requires enormous sample sizes ${ }^{4,8}$.

Previous studies of the effect of provider volumes on the outcomes of hip and knee replacement have shown mixed results with respect to both surgeon volume and institutional volume ${ }^{1-14}$. Furthermore, difficulty arises when attempts are made to compare the results of studies across different institutions and countries due to the different methods used for defining procedure volumes, as well as for handling case complexity and patient comorbidities. This lack of consistency coupled with differences in health care delivery have contributed to inconsistent findings.

Below we review and comment on the key TJR volume-outcome studies from England and North America, where most TJR surgeries are performed. Results from the American and Canadian studies are summarized in Tables 1 and 2. 


\section{The American experience}

Literature emerging from the United States has provided both the largest volume of data and greatest variation in results. The landmark study by Kreder et al $^{1}$ examining outcomes of total hip arthroplasty (THA) in Washington state between 1987-1991 demonstrated that low-volume surgeons experienced higher rates of mortality, infection, and revision arthroplasty when compared to high-volume surgeons. Low volume surgeons were defined as those performing less than $2 \mathrm{THA} /$ year and high-volume surgeons as those performing greater than 10 THA/year. Complication rates were adjusted for patient age, comorbidity, gender and diagnosis. Patients of low-volume surgeons also had a longer acute duration of hospitalization, which was 0.8 days longer than patients of high-volume surgeons. However, this effect was reversed with respect to institutional volume with low-volume hospitals demonstrating a shorter duration of hospital stay. This could be due to a variety of factors, such as low volume centers (which do not have inpatient rehabilitation services) having to discharge patients to outpatient rehabilitation facilities. It is also possible that high volume centers have more complex cases or patients with a greater number of comorbidities - factors which may not have been fully accounted for in data analysis. Interestingly, average costs for hospital services were found to be greater in low-volume centers, due primarily to relatively higher charges for implants and the operations as a whole. Overall, the majority of THAs in this study were performed by low-volume surgeons who comprised 170 of 494 (34.4\%) of the study population. The cut-off for center volumes was less than 16 for low-volume, and greater than 65 for high volumes. Volume categories for both surgeons and institutions were derived from the quartiles of the volume distributions. The second and third quartiles were collapsed into one group for comparison. Perhaps one of the most surprising results from this study is that over one third of all practicing surgeons performed an average of 2 or fewer THA/year. With such low average volumes, it is therefore not surprising that the complication rates among this group were significantly higher. Given the steady rise in rates of THA in the past decade, it is likely that the average numbers of low volume surgeons and centers have experienced a similar and parallel upward trend, possibly narrowing the difference in complication rates between the lowest and highest quartile surgeons.

Katz et al, who have extensively published on the volume-outcome relationship, studied the association between procedure volume and primary and revision THA outcomes in Medicare patients operated on in 1995-19962. Rather than use the data distributions to define procedure volume categories, hospital and surgeon volumes were stratified into what the authors described as clinically sensible categories. In their analysis, it was revealed that $52 \%$ of primary THAs and $77 \%$ of revisions were performed by surgeons doing 10 or fewer procedures a year. A strong association was found between low surgical volumes and increased complications. Surgeons in the low volume group $(<12 /$ year) compared to those in a high volume group ( $>50 /$ year) experienced higher rates of all complications examined including death, pneumonia, pulmonary embolism, myocardial infarction and deep infection with significant lower rates of dislocation and deep hip infection. Perhaps one of the most striking observations was the discrepant mortality rate for patients who underwent primary or revision THA by a surgeon performing greater than 10, as opposed to fewer than 3 , procedures per year. After adjusting for patient comorbidities, mortality rates for primary THA by a high volume surgeon were $0.7 \%$ versus $1.3 \%$ for low-volume surgeons. Mortality for revision THA was $1.5 \%$ for high volume surgeons as compared to $3.1 \%$ for low-volume 
surgeons. Similar increased complication rates were found for low volume surgical centers (<25 TKA/year) when compared to high volume centers (>200/year). While this study demonstrated a clear trend toward better outcomes with higher volumes, no specific recommendations were given on what might constitute an acceptable minimum number of procedures.

Shortly thereafter, Katz's group used Medicare data from 1995-1997 to study rates of revision within 3 years of primary THA $^{6}$. Hospitals were stratified into 4 volume groups: low (<25/year), medium (26-50/year and 51-100/year) and high (>100/year). Low volume surgeons were defined as those performing fewer than 12 primary THA/year. At the time of the study, $75 \%$ of all total hip replacements in the US were performed by surgeons doing less than 25/year, with centers performing over 100 cases a year accounting for only $10 \%$ of all hip replacements done. Comparing high volume surgeons ( $>12 /$ year) in high volume hospitals ( $>100 /$ year) to low volume surgeons $(<12 /$ year) and low volume centers ( $<25$ /year), the early failure rates were $3.3 \%$ vs $4.9 \%$, or approximately a $50 \%$ increase in revision surgery. The highest rates of revisions for low volume surgeons were found within the first 18 months.

SooHoo and Lieberman examined the effect of hospital volume on outcomes of total knee arthroplasty (TKA) in California from 1991-20018. They divided hospitals into three groups: low volume (bottom $40^{\text {th }}$ percentile), intermediate volume (middle $40^{\text {th }}$ percentile) and high volume (top $20^{\text {th }}$ percentile). Interestingly, the lowest volume centers (which accounted for $40 \%$ of the hospitals examined) averaged only 13 (standard deviation (SD) 5) TKA/year. This is in stark contrast to the intermediate group (50, SD 15) and high volume group (145, SD 47). Outcome measures included complications within the first 90 days and 365 days postoperatively. Statistically significant higher complication rates were found for low-volume centers across the outcomes measured, including mortality, readmission for infection, pulmonary embolism and thromboembolism.. The largest difference between the low and high volume centers was for infection $(1.13 \%$ versus $0.65 \%$, respectively; $\mathrm{p}=0.004)$. However, the overall postoperative complication rates remained relatively low, even among low-volume centers, leading authors to question the rationale behind regionalization for TKA.

Hervey et al examined provider volumes and patient outcomes in an analysis of primary and revision $\mathrm{TKAs}^{3}$. Using the Healthcare Cost and Utilization Project Nationwide Inpatient Sample (HCUP-NIS), they were the first to create a national data set from multiple states and hospital settings in order to generate more comprehensive and robust estimates. Hospitals were divided by volume cutoffs into 4 groups: those performing <85, 85-149, 150250, and $>250$ TKA/year. Surgeons were stratified from lowest to highest volumes into 4 groups: those performing <15, 15-30, 30-59, and >60 procedures/year. Interestingly, surgeons performing 30 or fewer primary TKAs/year were responsible for nearly half the surgical volume of knee replacements in the US. Using multivariate regression analysis, higher volume surgeons and hospitals had lower mortality rates. Rates of other complications were elevated in the low volume groups, but did not differ statistically from those in the highest-volume groups. The other major finding was that low volume surgeons and centers tended to discharge patients later than their higher volume counterparts, in contrast to the early findings of Kreder et $\mathrm{al}^{1}$.

Finally, Katz et al analyzed Medicare data on TKAs performed in Tennessee, Ohio, Illinois and North Carolina in 2000 to examine the effect of provider volume on patient function post-operatively7. Using a random sample of TKAs from various hospitals, patients were 
sent questionnaires capturing both self-reported WOMAC scores and surgery satisfaction scores. Poor WOMAC functional status scores $(<60)$ were noted to be more frequent among patients of surgeons who performed fewer than 12 TKA/year (20\%), and centers performing fewer than $10 \mathrm{TKA} /$ year (19\%), as compared to their higher-volume counterparts $(12 \%$ and $10 \%$ amongst high-volume surgeons and hospitals, respectively). These findings were consistent across the country, even after adjusting for medical comorbidities and age.

Overall, the American experience is quite unique in that across the country there is a virtual myriad of low volume centers that coexist with some of the largest and highest volume centers in the world. The current body of data indicates that despite increasing volume trends for THA and TKA, the majority of these procedures in the United States are still being performed by surgeons who perform fewer than 30/year and centers performing fewer than 100/year. Several studies have demonstrated increased complications rates, including increased risk of infection, revision, and mortality among low-volume surgeons and centers. In particular, it is evident that very low provider volumes (fewer than 10/year) are more frequently associated with increased morbidity and mortality. However, consensus on a minimum individual or institutional volume threshold for optimal patient outcomes has not been reached. The data are less conclusive with respect to the relationship between provider volumes and length of hospital stay, with early studies showing shorter stays in low-volume centers and subsequent studies the reverse. Little has been published on the financial costs of care in high versus lowvolume centers. Further such studies are needed.

\section{The English experience}

Judge et al examined the effects of hospital surgical volumes and teaching center status on the outcomes of total joint replacement between 1997 and 2002 in the United Kingdom, looking at over 280,000 hip and 211,000 knee replacements ${ }^{11}$. They used National Health Service Hospital Episode Statistics and defined hospital volume groups of <51, 51-100, 101$250,251-500$ and $>500$ procedures/year. They observed a decrease in patient mortality for both hip and knee replacement as volumes increased. Training institutions also had better THA outcomes, but no such effect was observed for TKA. Lower volume centers had longer lengths of stay.

This study demonstrated that overall, in contrast to the US, most arthroplasty surgery in England was being done in proportionally higher-volume centers. This was true for each of the six years studied. This finding is not surprising as it is easier to consolidate health care resources in a geographically smaller country. Further, over $80 \%$ of surgical services in the UK are publicly insured.

\section{The Canadian experience}

Results from Canadian volume-outcome studies have been mixed. Compared to their southern neighbors, Canadians have a more centralized medical delivery system, with more limited access to surgeons. On average, Canadian surgeons perform higher volumes than their American counterparts, resulting in relatively greater average annual procedure volumes among both surgeons and institutions. For example, surgeons performing greater than 25 procedures a year in Canada account for nearly $75 \%$ of the THA and TKA surgical volume ${ }^{14}$ whereas in the US, only one third of arthroplasties are performed by those doing over 25 procedures a year6. 
Kreder et al performed a study of THA using Ontario data from 199212. Surgeons and institutions were divided into 3 groups defined by the procedure volume distributions: $<40$ th, $40-80$ th, and $>80$ th percentile. The low surgeon volume group performed on average 9 THAs compared to the high volume group who performed on average over 27 THAs /year. Low volume centers performed $<40$ annual THAs compared to $>80$ /year in the high volume groups. Though Kreder attempted to use the procedure volume cut-offs from his earlier Washington study ${ }^{1}$, Canadian provider volumes were such that the vast majority of Canadian surgeons would have been labeled high-volume ( $>10$ procedures/year). The major finding of this study was that higher volume surgeons and centers discharged their patients much earlier (2.4 days earlier). No volume-outcome associations were found.

Kreder et al later looked at provider volume-outcome relations in Ontario TKAs from 19931996 using similar methods to the above study ${ }^{10}$. Again, patients of lower-volume surgeons had longer lengths of stay in hospital. They also had double the risk of reoperation.

Finally, Paterson et al performed a more recent, larger study of Ontario patients including over 20,000 THA patients and 27,000 TKA patients ${ }^{14}$. In the 10 years since Kreder's previous analysis, ${ }^{12}$ ? hip replacement volumes had grown by $50 \%$, and total knee replacement volumes by $100 \%$. The number of arthroplasty surgeons during that time period also increased, but at a much slower rate, resulting in an increased volume of cases per individual surgeon.

In this study, low-volume hip surgeons performed an average of 2-25 cases per annum, compared to 2-35 cases per annum for low-volume knee surgeons. This contrasted to the highvolume groups which were greater than 60 cases per annum for hip and greater than 71 cases per annum for knee. Of note, extremely low volume surgeons (defined as those performing less than 2 procedures/year) and low volume centers (defined as those performing less than 10 procedures/year) were excluded from analysis. The results of this study corroborated those of Kreder's earlier work in that no consistent relationships were found between complication rates and hospital volumes for either TKA or THA. Surgeons in the lowest volume quartile demonstrated a $30 \%$ increased rate of complications for THA but no similar relationship was seen for TKAs. Surgeon volume was also related to increased risk of revision for THA but not for TKA. Again, patients of lower-volume surgeons had relatively longer lengths of stay in hospital, although no similar relation was observed with hospital volumes.

Overall, the Canadian experience with respect to TJR surgical volume-outcome relationships is mixed. The differences in adverse outcome as related to provider volumes is much less pronounced than in the US, with the most recent Canadian study showing essentially no relations for TKA and inconsistent findings for THA. The one consistent finding among the Canadian studies is that, adjusting for hospital volume, patients of higher-volume surgeons have relatively shorter lengths of hospital stay.

\section{Discussion}

In summary, while the literature suggests that lower surgeon and hospital procedure volumes are associated with poorer short-term patient outcomes after $\mathrm{TJR}, 1-3,6,7,8,10,12,14$ this relationship appears to exist only when provider volumes are extremely low. The data among moderate and high volume providers is otherwise inconsistent with no clear relationship between surgeon or center experience and patient outcomes. Shorter hospital stays have also been observed among high volume surgeons and to a lesser extent among high volume centers $1,10,12,14$. 
These findings raise several points for consideration. The fact that extremely low provider volumes are associated with higher complication rates supports the notion of some minimum number of procedures that surgeons and surgical centers should perform in order to optimize outcomes. However, exactly where this threshold lies is difficult to determine from published reports. The fact that Canadian studies, where individual surgeons and centers perform relatively more procedures on average, generally fail to demonstrate a link between provider volumes and adverse outcomes suggest that few Canadian providers fall below this unidentified threshold. The association between surgeon procedure volume and decreased length of hospital stay (even after adjustment for hospital volume) does seem to be a reproducible finding and may be associated with lower costs for acute hospital care. It has been hypothesized that high volume surgeons and centers have more streamlined post-operative protocols and better access to rehabilitation and other ancillary services that could act to facilitate more rapid discharge ${ }^{1}$. Further research is needed to demonstrate whether there is a cost benefit to performing joint replacements in higher volume settings.

There is a global trend toward increasing surgeon and center procedure volumes in an effort to accommodate the fast-growing needs of an aging population. This increasing demand for joint replacement surgery has lead to the introduction of practice standards and protocols for everything from intake assessments, pre-operative work-up, surgical techniques, postoperative pain management and rehabilitation, which serve to streamline the care process and have contributed to significantly lower complication rates than seen in the previous two decades. The fact that complication rates are so low makes it harder to detect significant differences in outcomes related to provider volumes and also raises the question of whether small statistical differences in complication rates are of sufficient clinical importance to warrant the closure of low-volume centers in favor of high-volume regionalized centers of excellence. While small differences in outcomes, such as mortality, are likely to be important to patients, these must be weighted against potentially competing priorities such as access to service, inconvenience, and quality of life.

Other factors that may be contributing to heterogeneity among volume-outcome study findings are differences in the data used and patients studied. Most American studies have used Medicare data. In the US, Medicare covers selected patients (including those aged 65 years). This contrasts the Canadian and British public health insurance systems, which are universal. Consequently, it is likely that US Medicare patients undergoing TJR are, on average, older than Canadian and British TJR recipients. Furthermore, the US studies' reliance on Medicare data means that many private, high-volume clinics are excluded. When such centers are included, Medicare patients typically comprise a small percentage of total clinic and surgeon volumes. Thus, relative to Canadian and British studies, the American studies may be biased toward poorer outcomes, making volume-outcome relationships potentially easier to detect.

In summary, the relationship between TJR provider volumes and patient outcomes is complex. Based on intuition, it seems logical that surgeons and institutions that perform few procedures should have higher rates of complications, given the lack of familiarity, practice and available resources, such as rehabilitation and other ancillary services. US studies support this notion. However, there is no consensus regarding the number of procedures below which adverse patient outcomes (and possibly increased costs) would justify a change in policy. Further research and debate are needed to determine whether such a threshold exists and if so, where it lies. 


\begin{tabular}{|c|c|c|c|c|c|}
\hline Author & Year & Databases & Methods & $\begin{array}{c}\text { Volume } \\
\text { Categories }\end{array}$ & Results \\
\hline $\begin{array}{l}\text { Kreder et } \\
\mathrm{al}^{1}\end{array}$ & 1997 & $\begin{array}{l}\text { CHARS } \\
\text { computerized } \\
\text { data set of } \\
\text { Washington } \\
\text { State Health } \\
\text { Department }\end{array}$ & $\begin{array}{l}\text { Examined } \\
7936 \text { primary } \\
\text { THA between } \\
1988-1991\end{array}$ & $\begin{array}{l}3 \text { groups: low }<40 \\
\% \text { ile, medium } 40- \\
80 \% \text { ile and high } \\
>80 \% \text { ile } \\
\text { Surgeons: } \\
\text { Low: }<2 / \text { yr } \\
\text { Medium: } 2-10 / y r \\
\text { High: }>10 / y r \\
\text { Hospitals: } \\
\text { Low: }<16 / \text { yr } \\
\text { Medium: } 16- \\
65 / y r \\
\text { High: }>65 / y r\end{array}$ & $\begin{array}{l}\text { Low volume surgeons } \\
\text { experienced higher rates } \\
\text { of mortality, infection, } \\
\text { revision operations and } \\
\text { serious complications } \\
\text { during initial hospital } \\
\text { stay } \\
\text { High volume surgeons } \\
\text { demonstrates shorter } \\
\text { length of hospital stay } \\
\text { High volume centers } \\
\text { had longer average } \\
\text { length of hospital stay } \\
\text { Average cost per } \\
\text { procedure higher in low } \\
\text { volume centers }\end{array}$ \\
\hline \begin{tabular}{|l} 
Katz et \\
$\mathrm{al}^{2}$
\end{tabular} & 2007 & $\begin{array}{l}\text { Medicare } \\
\text { claims data }\end{array}$ & \begin{tabular}{|l} 
Examined \\
58,521 \\
primary THA \\
and 12,956 \\
revision THA \\
between July \\
$1995-J u n e$ \\
1996
\end{tabular} & $\begin{array}{l}\text { Surgeon volume: } \\
\text { Low: 1-3/yr } \\
\text { Medium: 4-10/yr } \\
\text { High: >10/yr } \\
\text { Hospital volume: } \\
1-5 / y r \\
6-10 / y r \\
11-25 / y r \\
26-50 / y r \\
>50 / y r\end{array}$ & $\begin{array}{l}\text { Higher hospital volume } \\
\text { associated with lower } \\
\text { rates of mortality and } \\
\text { dislocation following } \\
\text { primary THA } \\
\text { Higher surgeon volume } \\
\text { associated with lower } \\
\text { rate of dislocation and } \\
\text { deep hip infection } \\
\text { Similar results for } \\
\text { revision THA } \\
\text { Steady trend toward } \\
\text { better outcome } \\
\text { associated with higher } \\
\text { volume but no discrete } \\
\text { volume thresholds } \\
\text { identified }\end{array}$ \\
\hline $\begin{array}{l}\text { Hervey et } \\
\mathrm{al}^{3}\end{array}$ & 2003 & $\begin{array}{l}\text { Healthcare } \\
\text { Cost and } \\
\text { Utilization } \\
\text { Project } \\
\text { Nationwide } \\
\text { Inpatient } \\
\text { Sample }\end{array}$ & \begin{tabular}{|l} 
Examined \\
50,874 \\
primary TKA \\
and 4636 \\
revision TKA \\
performed in \\
1997
\end{tabular} & $\begin{array}{l}\text { Created } 4 \text { volume } \\
\text { groups for } \\
\text { surgeon and } \\
\text { hospital volume } \\
\text { to attain } \\
\text { approximately } \\
\text { equal percentages } \\
\text { in each category } \\
\text { Surgeon volume: } \\
<15 / \text { yr, } 15-29 / y r, \\
30-59 / \text { yr and } \\
>60 / y r \\
\text { Hospital volume: }\end{array}$ & $\begin{array}{l}\text { Higher surgeon and } \\
\text { hospital volumes } \\
\text { associated with lower } \\
\text { mortality } \\
\text { Surgeons performing } \\
<15 / \text { yr category } \\
\text { associated with } \\
\text { increased DVT risk and } \\
\text { post-operative infection } \\
\text { risk } \\
\text { No other relationship } \\
\text { between volume and } \\
\text { outcome }\end{array}$ \\
\hline
\end{tabular}




\begin{tabular}{|c|c|c|c|c|c|}
\hline & & & & \begin{tabular}{|l}
$<85 / y r, 85-149 / y r$ \\
$150-249 / y r$ and \\
$>250 / y r$ \\
No clear \\
definition of low \\
versus high \\
volume
\end{tabular} & \\
\hline \begin{tabular}{|l} 
Katz et \\
$\mathrm{al}^{5}$
\end{tabular} & 2004 & $\begin{array}{l}\text { Medicare } \\
\text { claims data }\end{array}$ & $\begin{array}{l}\text { Examined } \\
78,745 \\
\text { primary TKA } \\
\text { performed } \\
\text { between } \\
\text { January and } \\
\text { August } 2000\end{array}$ & $\begin{array}{l}\text { Surgeon volume: } \\
\text { 1-12/yr, 13-25/yr, } \\
26-50 / y r \text { and } \\
\text { >50/yr } \\
\text { Hospital volume: } \\
1-25 / y r, 26- \\
100 / y r, 101- \\
200 / y r \text { and } \\
>200 / y r \\
\text { No clear } \\
\text { definition of low } \\
\text { versus high } \\
\text { volume }\end{array}$ & $\begin{array}{l}\text { Highest volume centers } \\
\text { had lower risk of } \\
\text { pneumonia, dealth, PE } \\
\text { acute MI and infection } \\
\text { when compared to } \\
\text { lowest volume centers } \\
\text { Highest volume } \\
\text { surgeons compared to } \\
\text { lowest volume surgeons } \\
\text { had lower risks of } \\
\text { pneumonia and any } \\
\text { adverse outcome }\end{array}$ \\
\hline $\begin{array}{l}\text { Losina et } \\
\mathrm{al}^{6}\end{array}$ & 2003 & $\begin{array}{l}\text { Medicare } \\
\text { claims data }\end{array}$ & \begin{tabular}{|l} 
Examined \\
76,627 \\
primary THR \\
between July \\
1995 and June \\
1996
\end{tabular} & $\begin{array}{l}\text { Surgeon volume: } \\
\text { Low: <12/yr } \\
\text { Hospital volume: } \\
1-25 / y r \\
26-50 / y r \\
51-100 / y r \\
>100 / y r\end{array}$ & $\begin{array}{l}\text { Only looked at rate of } \\
\text { early failure requiring } \\
\text { revision surgery } \\
\text { Patients of low volume } \\
\text { surgeons more likely to } \\
\text { need revision THA } \\
\text { compared to high } \\
\text { volume surgeons } \\
\text { Strongest association } \\
\text { within first } 18 \text { months } \\
\text { suggesting technical } \\
\text { cause as mechanism of } \\
\text { early failure } \\
\text { Higher hospital volume } \\
\text { independently } \\
\text { associated with lower } \\
\text { failure rates }\end{array}$ \\
\hline $\begin{array}{l}\text { Katz et } \\
\mathrm{al}^{7}\end{array}$ & 2006 & $\begin{array}{l}\text { Medicare } \\
\text { claims data }\end{array}$ & \begin{tabular}{|l} 
Examined \\
functional \\
status of 932 \\
patients who \\
underwent \\
primary TKA
\end{tabular} & $\begin{array}{l}\text { Surgeon volume: } \\
\text { Low: } \leq 6 / \text { yr } \\
\text { Hospital volume: } \\
\text { Low: } \leq 25 / \text { yr }\end{array}$ & $\begin{array}{l}\text { Patients of low volume } \\
\text { surgeons and centers } \\
\text { were } 2 X \text { as likely to } \\
\text { report poor functional } \\
\text { score compared to high } \\
\text { volume surgeons and } \\
\text { centers } \\
\text { Lowest volume group } \\
2 X \text { as likely to have } \\
\text { decreased range of } \\
\text { motion }\end{array}$ \\
\hline
\end{tabular}




\begin{tabular}{|c|c|c|c|c|c|}
\hline & & & & & $\begin{array}{l}\text { No difference in pain or } \\
\text { level of satisfaction }\end{array}$ \\
\hline $\begin{array}{l}\text { SooHoo } \\
\text { et } \mathrm{al}^{8}\end{array}$ & 2006 & \begin{tabular}{|l|} 
California's \\
Office of \\
Statewide \\
Health \\
Planning and \\
Development \\
records
\end{tabular} & $\begin{array}{l}\text { Examined } \\
\text { discharge data } \\
\text { for } 222,684 \\
\text { primary TKA } \\
\text { between 1991- } \\
2001\end{array}$ & $\begin{array}{l}\text { Hospital volume: } \\
\text { Low (<40\%ile): } \\
\text { 13/yr } \\
\text { Intermediate (40- } \\
80 \% \text { ile): } 50 / \text { yr } \\
\text { High (>80\%ile): } \\
145 / y r\end{array}$ & $\begin{array}{l}\text { Low volume hospitals } \\
\text { had higher mortality in } \\
90 \text { days post discharge } \\
\text { and higher 90-day } \\
\text { readmission rate for } \\
\text { infection, pulmonary } \\
\text { embolism and } \\
\text { thrombophlebitis }\end{array}$ \\
\hline
\end{tabular}

Table 1. Summary of American TJR Volume-Outcome Studies

\begin{tabular}{|c|c|c|c|c|c|}
\hline Author & Year & Databases & Methods & $\begin{array}{c}\text { Volume } \\
\text { Categories }\end{array}$ & Results \\
\hline $\begin{array}{l}\text { Kreder et } \\
\mathrm{al}^{12}\end{array}$ & 1998 & \begin{tabular}{|l|} 
Canadian \\
Institute for \\
Health \\
Information \\
(CIHI) \\
Hospital \\
Discharge \\
Abstracts and \\
Ontario Health \\
Insurance Plan \\
(OHIP) \\
Physician \\
Service Claims
\end{tabular} & $\begin{array}{l}\text { Examined } 3645 \\
\text { patient with } \\
\text { elective THA in } \\
\text { Ontario in } 1992\end{array}$ & $\begin{array}{l}\text { Volumes } \\
\text { stratified } \\
\text { based on } \\
\text { percentiles } \\
\text { into } 3 \\
\text { categories - } \\
\text { low } \\
\text { (<40\%ile), } \\
\text { medium (40- } \\
80 \% \text { ile) and } \\
\text { high } \\
\text { (>80\%ile) } \\
\text { Surgeon } \\
\text { volume: } \\
\text { Low: <9/yr } \\
\text { Medium: } 9- \\
27 / y r \\
\text { High: }>27 / y r \\
\\
\text { Hospital } \\
\text { volume: } \\
\text { Low: <42/yr } \\
\text { Medium: 42- } \\
107 / y r \\
\text { High: } \\
>107 / y r\end{array}$ & $\begin{array}{l}\text { No difference in } \\
\text { complication rate } \\
\text { between low and high } \\
\text { volume categories } \\
\text { Patients of high volume } \\
\text { surgeons had shorter } \\
\text { length of hospital stay } \\
\text { with lowest volume } \\
\text { group averaging } 2.4 \\
\text { days longer in hospital } \\
\text { than highest volume } \\
\text { group } \\
\text { Hospital volume not } \\
\text { related to length of stay }\end{array}$ \\
\hline $\begin{array}{l}\text { Kreder et } \\
\mathrm{al}^{10}\end{array}$ & 2003 & $\begin{array}{l}\text { CIHI Hospital } \\
\text { Discharge } \\
\text { Abstracts and } \\
\text { Ontario Health } \\
\text { Insurance Plan }\end{array}$ & $\begin{array}{l}\text { Examined } \\
14,352 \text { patients } \\
\text { with elective } \\
\text { TKA between } \\
\text { 1993-1996 }\end{array}$ & $\begin{array}{l}\text { Volumes } \\
\text { stratified } \\
\text { based on } \\
\text { percentiles } \\
\text { into 3 }\end{array}$ & $\begin{array}{l}\text { No effect of provider } \\
\text { volume on infection or } \\
\text { mortality } \\
\text { Low volume groups } \\
\text { (both surgeon and } \\
\text { center) had longer } \\
\end{array}$ \\
\hline
\end{tabular}




\begin{tabular}{|c|c|c|c|c|c|}
\hline & & \begin{tabular}{|l|} 
(OHIP) \\
Physician \\
Service Claims
\end{tabular} & & $\begin{array}{l}\text { categories - } \\
\text { low } \\
\text { (<40\%ile), } \\
\text { medium (40- } \\
80 \% \text { ile) and } \\
\text { high } \\
\text { (>80\%ile) } \\
\text { Low: <14/yr } \\
\text { Medium: 14- } \\
42 / y r \\
\text { High: >42/yr } \\
\text { Hospital } \\
\text { volume: } \\
\text { Low: <48/yr } \\
\text { Medium: 48- } \\
120 / y r \\
\text { High: } \\
>120 / y r\end{array}$ & $\begin{array}{l}\text { hospital stays } \\
\text { Higher revision rates } \\
\text { seen in low volume } \\
\text { hospitals } \\
\text { No association between } \\
\text { revision rate and } \\
\text { surgeon volume }\end{array}$ \\
\hline $\begin{array}{l}\text { Paterson et } \\
\mathrm{al}^{14}\end{array}$ & 2010 & $\begin{array}{l}\text { CIHI Hospital } \\
\text { Discharge } \\
\text { Abstracts and } \\
\text { Ontario Health } \\
\text { Insurance Plan } \\
\text { (OHIP) } \\
\text { Physician } \\
\text { Service Claims }\end{array}$ & $\begin{array}{l}\text { Examined } \\
\text { 20,290 THA } \\
\text { and 27,217 TKA } \\
\text { patients } \\
\text { between April } \\
\text { 2000-March } \\
2004\end{array}$ & $\begin{array}{l}\text { Hospital and } \\
\text { surgeon } \\
\text { volumes } \\
\text { divided } \\
\text { based on } \\
\text { quartile } \\
\text { distribution } \\
\text { Surgeon } \\
\text { volume: 2- } \\
25 / \text { yr, 26- } \\
40 / \text { yr, 41- } \\
60 / \text { yr and } \\
>60 / y r \\
\text { Hospital } \\
\text { volume: 10- } \\
110 / \text { yr, 111- } \\
150 / \text { yr, 151- } \\
225 / \text { yr and } \\
>225 / y r \\
\\
\text { Extremely } \\
\text { low volume } \\
\text { groups } \\
\text { (surgeons } \\
<2 / \text { yr and } \\
\text { hospitals } \\
<10 / y r \text { ) } \\
\text { excluded }\end{array}$ & $\begin{array}{l}\text { Higher volume } \\
\text { surgeons had relative } \\
\text { shorter length of } \\
\text { hospital stay for both } \\
\text { TKA and THA } \\
\text { No association between } \\
\text { hospital volume and } \\
\text { length of stay for either } \\
\text { procedure } \\
\text { No relationship found } \\
\text { between hospital } \\
\text { volume and rate of } \\
\text { complications } \\
\text { Lowest volume } \\
\text { surgeons only had } \\
\text { increased complication } \\
\text { rates for THA but not } \\
\text { TKA } \\
\text { Low volume surgeons } \\
\text { had higher rates of } \\
\text { revision for THA }\end{array}$ \\
\hline
\end{tabular}

Table 2. Summary of Canadian TJR Volume-Outcome Studies 


\section{References}

Gawande, A. (2003). Complications: a surgeon's notes on an imperfect science. Metropolitan Books.

Hagen, T.P., Vaughan-Sarrazin, M., \& Cram, P. (2010). Relation between hospital orthopaedic specialization and outcomes in patients aged 65 and older:retrospective analysis of US Medicare data. Br Medical J. Pp. 340:c165.

Hervey, S.I., Purves, H.R., Guller, U., Toth, A.P., Vail, T.P., \& Pietrobon, R. (2003). Provider Volume of Total Knee Arthroplasties and Patient Outcomes in the HCUPNationwide Inpatient Sample. J Bone Joint Surg Am. Pp. 85:1775-83.

Judge, A., Chard, J., Learmonth, I., \& Dieppe, P. (2006). The effects of surgical volumes and training centre status on outcomes following total joint replacement: analysis of the Hospital Episode Statistics for England. J of Public Health..

Katz, J.N., Losina, E., Barrett, J., Phillips, C.B., Mahomed, N.N., Lew, R., Guadagnoli, E., Harris, W.H., Poss, R., \& Baron, J.A. (2001). Association Between Hospital and Surgeon Procedure Volume and Outcomes of Total Hip Replacement in the United States Medicare Population. J Bone Joint Surg Am. Pp 83:1622-29.

Katz, J.N., Barrett, J., Mahomed, N.N., Baron, J.A., Wright, J., \& Losina, E. (2004). Association Between Hospital and Surgeon Procedure Volume and the Outcomes of Total Knee Replacement. J Bone Joint Surg Am. Pp. 86:1909-16.

Katz, J.N., Mahomed, N.N., Baron, J.A., Barrett, J.A., Fossel, A.H., Creel, A.H., Wright, J., Wright, E.A., \& Losine, E. (2007). Association of Hospital and Surgeon Procedure Volume With Patient-Centered Outcomes of Total Knee Replacement in a Population-Based Cohort of Patients Age 65 Years and Older. Arthritis and Rheumatism.Pp. 56(2):568-574.

Kreder, H.J., Deyo, R.A., Koepsell T., Swiontkowski, M.F., \& Kreuter, W. (1997). Relationship between the Volume of Total Hip Replacement Performed by Providers and the Rates of Postoperative Complications in the State of Washington. J Bone Joint Surg Am. Pp 79:485-94.

Kreder, H.J., Williams, J.I., Jaglal, S., Hu, R., Axcell, T., \& Stephen, D. (1998). Are Complication Rates for Elective Primary Total Hip Arthroplasty in Ontario Related to Surgeon and Hospital Volumes? A Preliminary Investigation. Can J Surg. Pp. 41(6):431-7.

Kreder, H.J., Grosso, P., Williams, J., Jangial, S., Axcell, T., Wai, E.K., \& Stephen, D.J.G. (2003). Provider volume and other predictors of outcome after total knee arthroplasty: a population study in Ontario. Can J Surg. Pp. 46(1):15-21.

Losina, E., Barrett, J., Mahomed, N.N., Baron, J.A., \& Katz, J.N. (2004). Early Failures of Total Hip Replacement. Arthritis and Rheumatism. Pp. 50(4):1338-43.

Mahomed, N.N., Barrett, J.A., Katz, J.N., Phillips, C.B., Losina, E., Lew, R.A., Guadagnoli, E., Harris, W.H., Poss, R. \& Baron, J.A. (2003). Rates and Outcomes of Primary and Revision Total Hip Replacement in the United States Medicare Population. J Bone Joint Surg Am. Pp. 85:27-32.

Patterson, J.M., Williams, J.I., Kreder, H.J., Mahomed, N.N., Gunraj, N., Wang, X., \& Laupacis, A. (2010). Provider volumes and early outcomes of primary total joint replacement in Ontario. Can J Surg. Pp. 53(3):175-83.

SooHoo, N.F., Zingmond, D.S., Lieberman, J.R., \& Ko, C.Y. (2006). Primary Total Knee Arthroplasty in California 1991 to 2001. J of Arthroplasty. Pp. 21(2):199-205. 
Zhan, C., Kaczmarek, R., Loyo-Berrios, N., Sangl, J., \& Bright, R.A. (2007). Incidence and Short-Term Outcomes of Primary and Revision Hip Replacement in the United States. J Bone Joint Surg Am. Pp. 89:526-33. 


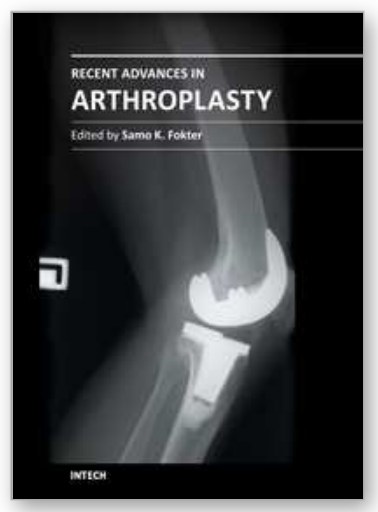

\author{
Recent Advances in Arthroplasty \\ Edited by Dr. Samo Fokter
}

ISBN 978-953-307-990-5

Hard cover, 614 pages

Publisher InTech

Published online 27, January, 2012

Published in print edition January, 2012

The purpose of this book was to offer an overview of recent insights into the current state of arthroplasty. The tremendous long term success of Sir Charnley's total hip arthroplasty has encouraged many researchers to treat pain, improve function and create solutions for higher quality of life. Indeed and as described in a special chapter of this book, arthroplasty is an emerging field in the joints of upper extremity and spine. However, there are inborn complications in any foreign design brought to the human body. First, in the chapter on infections we endeavor to provide a comprehensive, up-to-date analysis and description of the management of this difficult problem. Second, the immune system is faced with a strange material coming in huge amounts of micro-particles from the tribology code. Therefore, great attention to the problem of aseptic loosening has been addressed in special chapters on loosening and on materials currently available for arthroplasty.

\title{
How to reference
}

In order to correctly reference this scholarly work, feel free to copy and paste the following:

S. Rodriguez-Elizalde, R. Jenkinson, H. Kreder and J.M. Paterson (2012). Provider Volumes and Surgical Outcomes in Total Hip and Knee Replacement, Recent Advances in Arthroplasty, Dr. Samo Fokter (Ed.), ISBN: 978-953-307-990-5, InTech, Available from: http://www.intechopen.com/books/recent-advances-inarthroplasty/provider-volumes-and-surgical-outcomes-in-total-hip-and-knee-replacement

\section{INTECH}

open science | open minds

\author{
InTech Europe \\ University Campus STeP Ri \\ Slavka Krautzeka 83/A \\ 51000 Rijeka, Croatia \\ Phone: +385 (51) 770447 \\ Fax: +385 (51) 686166 \\ www.intechopen.com
}

\author{
InTech China \\ Unit 405, Office Block, Hotel Equatorial Shanghai \\ No.65, Yan An Road (West), Shanghai, 200040, China \\ 中国上海市延安西路65号上海国际贵都大饭店办公楼 405 单元 \\ Phone: +86-21-62489820 \\ Fax: +86-21-62489821
}


(C) 2012 The Author(s). Licensee IntechOpen. This is an open access article distributed under the terms of the Creative Commons Attribution 3.0 License, which permits unrestricted use, distribution, and reproduction in any medium, provided the original work is properly cited. 